\title{
The evaluation of the relationship between fetuin-A and traditional and non-traditional cardiovascular risk factors in kidney transplantation recipients
}

\author{
Nizameddin Koca $^{1} \odot$, Alparslan Ersoy ${ }^{2}$, Barıș Şensoy ${ }^{3} \odot$, Emine Kırhan $^{4} \odot$, Sümeyye Güllülü̈${ }^{5}$, \\ Melahat Dirican ${ }^{6} \odot$, Emre Sarandöl ${ }^{6} \odot$
}

${ }^{1}$ Department of Internal Medicine, University of Health Sciences, Bursa Yüksek Ihtisas Training and Research Hospital, Bursa, Turkey ${ }^{2}$ Department of Nephrology \& Transplantation, Uludağ University School of Medicine, Bursa, Turkey

${ }^{3}$ Department of Cardiology, University of Health Sciences, Bursa Yüksek İhtisas Training and Research Hospital, Bursa, Turkey

${ }^{4}$ Department of Biochemistry, Tavşanlı State Hospital, Kütahya, Turkey

${ }^{5}$ Department of Cardiology, Uludăg University School of Medicine, Bursa, Turkey

${ }^{6}$ Department of Biochemistry, Uludağ University School of Medicine, Bursa, Turkey

DOI: $10.18621 /$ eurj.572606

\begin{abstract}
Objectives: Kidney transplantation recipients (KTRs) have higher cardiovascular complications risk compared to the general population. Cardiovascular risk factors (CVRF, Traditional and non-traditional) are widely studied to understand the causes of increased cardiovascular disease (CVD) risk in KTRs. Fetuin-A prevents from vascular calcification (VC) by inhibiting production and collapsing of apatite crystals to the vascular wall. The relationship between fetuin-A levels and CVRF in KTRs was investigated in this study.

Methods: Sixty-two KTRs with no prior CVD history participated. Anthropometrical, laboratory (fetuin-A, inflammation markers, antioxidants, lipid peroxidation products) and cardiological (echocardiographic, pulse wave velocity) measurements were performed. Participants were divided into two groups according to normal ( $\geq 0.5 \mathrm{~g} / \mathrm{L}, \mathrm{n}=32, \mathrm{NFA})$ and low $(<0.5 \mathrm{~g} / \mathrm{L}, \mathrm{n}=30$, LFA) fetuin-A levels according to manufacturer's reference range, and the results were compared.

Results: No significant difference was observed in demographic features, body mass index, systolic and diastolic blood pressures, left ventricle mass index, waist and hip circumferences, left ventricle hypertrophy and waist-hip ratios between the two groups $(p>0.05)$. The ratios of drug usage such as immunosuppressives, anti-hypertensives and statin were comparable between two groups. Parathormone levels were significantly higher in the NFA group $(p=0.015)$ and glomerular filtration rate was calculated significantly higher in LFA group $(p=007)$. The comparison of other CVRF reveals no significant difference $(p>0.05)$.

Conclusions: Although many CVRF improved in KTRs, subclinical inflammation markers were still higher than the healthy population. Identification and early recognition of CVRF in high-risk individuals may contribute to the reduction of cardiovascular mortality. In our study, we observed no significant relationship between fetuin-A levels and CVRFs. We evaluated the relationship between serum fetuin-A levels on cardiovascular risk factors by its role in pathophysiology.
\end{abstract}

Keywords: Kidney transplantation, cardiovascular risk factor, fetuin A

Received: May 31, 2019; Accepted: June 26, 2019; Published Online: August 7, 2019

Address for correspondence: Nizameddin Koca, MD., Assistant Professor, Bursa Yüksek İhtisas Training and Research Hospital, Department of Internal Medicine, Bursa, Turkey

E-mail: nizameddin.koca@sbu.edu.tr 
$\mathrm{T}$ he most common cause of death in dialysis patients is cardiovascular disease (CVD) [1]. Although CVD risk after a successful kidney transplantation decrease compared with waitlisted patients on dialysis, transplant patients still have high risk of vascular complications compared with the general population $[1,2]$. The causes of increased CVD risk in recipients are an exacerbation of traditional risk factors [advanced age, male gender, low HDL cholesterol, diabetes mellitus, smoking, race, family history, left ventricular hypertrophy (LVH), dialysis vintage, hypertension, increased low density lipoprotein (LDL) cholesterol, menopause, low levels of physical activity] due to the effect of immunosuppressive drugs, and non-traditional risk factors [proteinuria, hyperhomocysteinemia, elevated levels of lipoprotein (a) and apolipoprotein $\mathrm{A}$ isoforms, anemia, abnormal calcium (Ca) and phosphorous (P) metabolism, extracellular volume overload, oxidative stress, inflammation (elevated C-reactive protein and interleukin-6 levels), malnutrition, thrombogenic factors, sleep disorders, nitric oxide and endothelin balance changes] related to immunosuppressive drugs or to chronic kidney disease (CKD) [3, 4].

Vascular calcification (VC) and inflammationare common complicationscontributed to the development of CVD in patients with CKD.Disturbances of $\mathrm{Ca}$ and $\mathrm{P}$ homeostasis may induce calcification processes in these patients. Other factors related with the pathogenesis of VC in CKD include increased duration of uremia, increased dialysis vintage, low serum fetuin-A level and high serum level of fibroblast growth factor 23 (FGF23) [5]. Inflammation in CKD patients may contribute to endothelial dysfunction that observed in patients even in the early stages of the disease, and accelerated atherosclerosis [6]. In addition, inflammationis associated with $\mathrm{VC}$ or valvular calcification in $\mathrm{CKD}$ patients [7]. The presence of $\mathrm{VC}$ in hemodialysis patients is associated with increased stiffness of large capacitative elastic-type arteries like common carotid artery and aorta [8]. Arterial stiffness (AS) is known to occur before the onset of clinical disease in CKD patients and it is an independent risk factor for CVD. Transplantation improves large and to some extent small artery elasticities.Damaged large arterial compliance has an important role in the genesis of high systolic blood pressure (BP), high pulse pressure and increased $\mathrm{LVH}$, while small arterial elasticity is related to endothelial dysfunction [9].

Fetuin-A is a glycoprotein that prevent from VC by inhibiting production and collapsing of apatite crystals to the vascular wall. Fetuin-A levels found to be very low in patients with kidney failure who have high risk for $\mathrm{VC}$, and increased CVD frequency can be related with low fetuin-A levels in hemodialysis patients [10]. It is remarkable that inflammation markers related VC is seen in transplant recipients rather than traditional risk factor related AS [11]. The present study aimed to evaluate the relationship between serum fetuin-A levels with traditional and non-traditional CVD risk factors in transplant recipients.

\section{METHODS}

The cohort includedstable consecutive kidney transplant recipients who were older than 18 years and on regular outpatient clinic visits. We used the following exclusion criterias; presence of known CVD (coronary artery disease, heart failure, peripheral vascular disease, prior myocardial infarction), acute or chronic liver disease, any inflammatory disease, malignancy and history of hospitalization or surgery within the preceding 6 months. The study was carried out in accordance with Good Clinical Practice and the Declaration of Helsinki. The local ethics committee approved the study protocol and informed written consent was obtained from all individuals before they entered the study. Anamnestic information retrieved from all participants. A complete physical examination was performed to all recipients.

Normal fetuin-A serum concentrations (ninetyfive percentile) range between 0.5 and $1.0 \mathrm{~g} / \mathrm{L}$ with a mean value of $0.733 \mathrm{~g} / \mathrm{L}$ and a standard deviation of $0.178 \mathrm{~g} / \mathrm{L}$. Kidney recipients were divided into two groups with normal ( $\geq 0.5 \mathrm{~g} / \mathrm{L}, \mathrm{n}=32$, NFA) and low $(<0.5 \mathrm{~g} / \mathrm{L}, \mathrm{n}=30, \mathrm{LFA})$ fetuin-A levels.

\section{Anthropometrical Measurements and Definitions}

In all patients, body weight, waist (WC) and hip circumferences (HCs) were measured. WC was measured at the umbilicus level after normal breath to the nearest $0.1 \mathrm{~cm}$. HC was measured at the most salient point between the waist and the thigh. Height was measured to nearest $0.1 \mathrm{~cm}$ and weight measured using a digital scale to nearest $0.1 \mathrm{~kg}$. Body mass 
index (BMI) was calculated as weight in kilograms divided by the square of height in meters [weight $/$ height $^{2}\left(\mathrm{~kg} / \mathrm{m}^{2}\right)$ ]. The BMI was classified using the adult scheme proposed by the World Health Organization (WHO), which defines obesity as a BMI $\geq 30 \mathrm{~kg} / \mathrm{m}^{2}$ [12]. Abdominal obesity was defined using WC points of $>102 \mathrm{~cm}$ for men and $>88 \mathrm{~cm}$ for women.

\section{Blood Pressure Measurements}

Systolic and diastolic BPs were measured by one of the study investigators using standard mercury sphygmomanometer. BP cuffs of an appropriate size for each subject were attached to the upper arms. BP was measured in the arms over the brachial arteries. BPs were measuredfrom firstly right arm or arm without fistula in recipients with arterio-venous fistula.

\section{Laboratory Measurements}

Venous blood samples were taken after an overnight fasting. Routine biochemical and hematological parameters were studied on the day that the blood was collected. Plasma samples were centrifuged and frozen in aliquots at $-80{ }^{\circ} \mathrm{C}$ until other assays were performed. Complete blood count (with CELL-DYN 3700), the levels of serum glucose, urea, creatinine, uric acid, $\mathrm{Ca}, \mathrm{P}$ (by enzymatic method), total cholesterol (T-chol), triglyceride (by enzymatic hydrolyse method) and high-density lipoprotein (HDL) cholesterol (by enzymatic elimination method) were measured with Abbott kit in Aeroset device. LDL cholesterol was calculated with Friedewald formula [13].

Serum intact parathyroid hormone (iPTH) measured by immunoassay with Immulite 2000 AnalyserDpc. High-sensitive C-reactive protein (hsCRP) measured with solid phase chemiluminesans immune measurement method by Immulite 2500 kits in Immulite 2500 device. 24-hour urinary protein excretion (UPE) was measured by immunoassay (DCA 2000 system, Siemens AG, Munich, Germany). We calculated estimated glomerular filtration rate (eGFR) using 2009 the Chronic Kidney Disease Epidemiology Collaboration (CKD-EPI) creatinine equation [14]. Bone mineral density (BMD) was measured with DEXA method (Hologic QDR-2000, Waltham, MA, USA) from femoral and lumbar regions.Anemia after transplantation defined as hemoglobin falls to less than $11 \mathrm{~g} / \mathrm{dL}$ in premenopausal females or to less than $12 \mathrm{~g} / \mathrm{dL}$ in males and postmenopausal females [15]. Inflammation markers [interleukin 6 and 8 (IL-6, IL-8), tumor necrosis factor alpha (TNF- $\alpha$ ), fibronectin, transforming growth factor beta (TGF- $\beta$ )], antioxidant enzymes [whole blood glutathione peroxidase (Gpx), serum superoxide dismutase (SOD) and total antioxidant status (TAOC)], antioxidants (vitamin C) and lipid peroxidation products [red blood cell malondialdehyde (RBC MDA)] were measured.

Serum fetuin-A levels were measured byan enzyme-linked immunosorbent assay (ELISA) kit for human fetuin-A (BioVendor Laboratory Medicine, Brno, Czech Republic) according to manufacturer's instructions. Intra- and inter-assay coefficients of variation were both less than $5.0 \%$. Normal serum concentrations of fetuin-A in healthy adults range between 0.5 and $1.0 \mathrm{~g} / \mathrm{L}$ [16].

\section{Cardiac Measurements}

The cardiac parameter's measurement in recipients was performed by the same physician at the lab of cardiology department. Echocardiographic measurements were done with Vivid 3 device (General Electrics, Vivid 3 echocardiography, Milwaukee, WI, USA). Left ventricle mass index (LVMI) was calculated by division of left ventricle mass calculated with Dewereux [13] formula (Left ventricle mass (g) $\left.=0.8 \times 1.04 \times\left[\left(\mathrm{LviDD}^{2} \mathrm{IVS}+\mathrm{PWT}\right)^{3}-\mathrm{LviDD}^{3}\right]+0.6\right)$ to body surface area with Mostellar formula [17] ( $\sqrt{ }$ height $\times$ weight $/ 3600$ ). LVMI $\geq 110 \mathrm{~g} / \mathrm{m}^{2}$ and $\geq 134$ $\mathrm{g} / \mathrm{m}^{2}$ is accepted as LVH in women and men, respectively. All AS measurements were performed on radial artery. Stroke volume, cardiac output, systemic vascular resistance impedance and large/small vascular elasticity indexes were measured with PulseWave Sensor HDI (Hypertension Diagnostics, Eagan, MN).

\section{Statistical Analysis}

The data was analyzed using the IBM SPSS Software package of version 23.0 (IBM Corp, Armonk, NY, USA) licensed to Uludag University. Normality of variables was assessed by the Shapiro Wilk's normality test. Categorical variables were given as number and percentage, and numerical variables as mean \pm standard deviation or median 
(minimum-maximum). Continuous variables were compared using the parametric two independent samples t-test or the non-parametric Mann-Whitney test in intergroup comparisons. Chi square test and Fisher-Freeman-Halton test were used to test the differences in proportion of the categorical variables. Associations between variables were estimated using Pearson or Spearman correlation coefficients. A $p$ value less than 0.05 was considered to be significant.

\section{RESULTS}

\section{Characteristics of recipients}

The cause of chronic kidney disease in 23 recipients was unknown. The primary disease of the rest was glomerulonephritis $(\mathrm{n}=8)$, diabetic nephropathy $(\mathrm{n}=2)$, hypertensive nephropathy $(\mathrm{n}=$ $11)$, obstructive nephropathy with vesicoureteral reflux $(n=6)$, polycystic kidney disease $(n=5)$, nephrolithiasis $(n=3)$ and rare diseases $(n=4)$. Before kidney transplantation, 42 patients were on hemodialysis (HD), 8 patients were on peritoneal dialysis (PD), 7 patients were converted from PD to $\mathrm{HD}$ and 5 patients underwent preemptive transplantation. Mean dialysis durations were $44.1 \pm$ 5.2 months. All patients underwent first kidney transplantation and mean follow-up time after transplantation was $36.9 \pm 4.8$ months. Numbers of diabetic and hypertensive recipients were 12 and 44, respectively.

There was no significant difference between demographic features of the two groups (Table 1). The ratios of drug usage such as immunosuppressives, anti-hypertensives and statin were comparable between two groups. Also, BMI, systolic and diastolic BPs, LVMI, waist and hip diameters, LVH and WHRs of the groups were similar (Table 1). LVMI was 145.9 $\pm 22.1 \mathrm{~g} / \mathrm{m}^{2}$ (min-max: 110-187) in patients with LVH $(\mathrm{n}=27)$ and $107.3 \pm 19.4 \mathrm{~g} / \mathrm{m}^{2}(\min -\max : 62.9-133.7)$ in patients without LVH $(\mathrm{n}=35), p<0.001$. Family history for HT, DM, CAD and obesity was similar (Table 1).

Table 1. Comparison of Demographic data and traditional cardiovascular risk factors between the groups with normal and low fetuin-A levels

\begin{tabular}{lccc}
\hline & Normal $(\mathbf{n}=\mathbf{3 2})$ & Low $(\mathbf{n}=\mathbf{3 0})$ & $\boldsymbol{p}$ value \\
\hline Male/female ratio & $13 / 19$ & $16 / 14$ & 0.316 \\
Age (years) & $37.9 \pm 10.3$ & $37.7 \pm 11.9$ & 0.934 \\
Dialysis duration, [months, median (min-max)] & $34.5(0-145)$ & $31(0-190)$ & 0.925 \\
Dialysis modality, n (\%) & & & 0.480 \\
HD & $20(62.5)$ & $22(73.3)$ & \\
PD & $5(15.6)$ & $3(10)$ & \\
HD+PD & $3(9.4)$ & $4(13.3)$ & \\
Pre-emptive & $4(12.5)$ & $1(3.3)$ & \\
Donor type (living/deceased) & $19 / 13$ & $18 / 12$ & 0.960 \\
Donor age, [years, median (min-max)] & $50.5(15-73)$ & $46.5(11-62)$ & 0.179 \\
Transplant duration [months, median (min-max)] & $16.5(7-147)$ & $23(6-157)$ & 0.388 \\
HT, n (\%) & $24(75)$ & $20(66.7)$ & 0.470 \\
DM, n (\%) & $7(21.9)$ & $5(16.7)$ & 0.604 \\
CAD, n (\%) & - & $1(3)$ & 0.298 \\
Obesity, n (\%) & $3(9.4)$ & $8(26.7)$ & 0.075 \\
Abdominal obesity, n (\%) & $13(40.6)$ & $16(53.3)$ & 0.316 \\
Smoker (n, \%) & $2(6.3)$ & $4(13.3)$ & 0.346 \\
Physical activity, n (\%) & $15(46.9)$ & $20(66.7)$ & 0.116 \\
\hline
\end{tabular}


Table 1 Continued.

\begin{tabular}{|c|c|c|c|}
\hline \multicolumn{4}{|l|}{ Medication History } \\
\hline Immunosuppressive regimens, $\mathrm{n}(\%)$ & & & 0.167 \\
\hline Tac $+M M F+P$ & $18(56.3)$ & $17(56.7)$ & \\
\hline $\mathrm{CsA}+\mathrm{MMF}+\mathrm{P}$ & $5(15.5)$ & $8(26.7)$ & \\
\hline $\mathrm{Tac}+\mathrm{AZA}+\mathrm{P}$ & - & $2(6.7)$ & \\
\hline $\mathrm{CsA}+\mathrm{AZA}+\mathrm{P}$ & $2(6.3)$ & - & \\
\hline $\mathrm{Tac}+\mathrm{P}$ & - & $2(6.7)$ & \\
\hline $\mathrm{EVR}+\mathrm{CsA}+\mathrm{P}$ & $1(3.1)$ & - & \\
\hline $\mathrm{EVR}+\mathrm{Tac}+\mathrm{P}$ & $3(9.4)$ & $1(3.3)$ & \\
\hline $\mathrm{EVR}+\mathrm{MMF}+\mathrm{P}$ & $1(3.1)$ & - & \\
\hline $\mathrm{SRL}+\mathrm{MMF}+\mathrm{P}$ & $2(6.3)$ & - & \\
\hline Statin use, n (\%) & $6(18.7)$ & $4(13.3)$ & 0.409 \\
\hline \multicolumn{4}{|l|}{ Anti-hypertensive, n (\%) } \\
\hline None & $8(25)$ & $10(33)$ & 0.470 \\
\hline Combination & $16(50)$ & $14(46)$ & 0.793 \\
\hline ACEI or ARB & $9(28)$ & $7(23)$ & 0.667 \\
\hline$\beta$-Blocker & $15(46)$ & $7(23)$ & 0.053 \\
\hline$\alpha$-Blocker & $1(3)$ & $5(16)$ & 0.071 \\
\hline $\mathrm{CaCB}$ & $19(59)$ & $16(53)$ & 0.632 \\
\hline \multicolumn{4}{|l|}{ Family history, n (\%) } \\
\hline HT & $10(31.3)$ & $7(23.3)$ & 0.485 \\
\hline $\mathrm{DM}$ & $7(21.9)$ & $5(16.7)$ & 0.604 \\
\hline CAD & $8(25)$ & $5(16.7)$ & 0.421 \\
\hline Obesity & $6(18.8)$ & $9(30)$ & 0.301 \\
\hline \multicolumn{4}{|l|}{ Measurements } \\
\hline $\operatorname{BMI}\left(\mathrm{kg} / \mathrm{m}^{2}\right)$ & $25.3 \pm 3.6$ & $26.5 \pm 5.4$ & 0.295 \\
\hline Systolic BP (mmHg) & $136.2 \pm 18.1$ & $133.1 \pm 15.8$ & 0.485 \\
\hline Diastolic BP (mmHg) & $81.3 \pm 11.2$ & $78.2 \pm 12.2$ & 0.300 \\
\hline Waist circumference $(\mathrm{cm})$ & $93.2 \pm 10.2$ & $95.0 \pm 14.1$ & 0.570 \\
\hline Hip circumference $(\mathrm{cm})$ & $101.5 \pm 9.5$ & $105.7 \pm 11.6$ & 0.127 \\
\hline Waist to hip ratio & $0.91 \pm 0.07$ & $0.89 \pm 0.06$ & 0.204 \\
\hline
\end{tabular}

$\mathrm{HD}=$ hemodialysis, $\mathrm{PD}=$ peritoneal dialysis, $\mathrm{Tac}=$ tacrolimus, $\mathrm{MMF}=$ mycophenolate mofetil or sodium, $\mathrm{P}=$ prednisolone, $\mathrm{CsA}=$ cyclosporine, $\mathrm{AZA}=$ azathioprine, $\mathrm{EVR}=$ everolimus, $\mathrm{SRL}=$ sirolimus, $\mathrm{ACEI}=$ angiotensin converting enzyme inhibitor, $\mathrm{ARB}=$ angiotensin receptor blocker, $\mathrm{CaCB}=$ calcium channel blocker $\mathrm{HT}=$ hypertension, $\mathrm{DM}=$ diabetes mellitus, $\mathrm{CAD}=$ coronary artery disease, $\mathrm{BMI}=$ body mass index, $\mathrm{BP}=$ blood pressure

\section{Treatments}

All patients were treated with tacrolimus (Tac, 0.05-0.1 mg/kg/d, $\mathrm{n}=43$ ) or cyclosporine A (CsA, 6 $\mathrm{mg} / \mathrm{kg} / \mathrm{d}, \mathrm{n}=16$ ) or mammalian target of rapamycin (mTOR) (everolimus, $\mathrm{n}=6$ or sirolimus, $\mathrm{n}=2$ ) combined mycophenolic acid (1440 mg/d) or mycophenolate mofetil $(2 \mathrm{~g} / \mathrm{d})(\mathrm{n}=51)$ or azathioprine $(100 \mathrm{mg} / \mathrm{d}, \mathrm{n}=4)$ and corticosteroids (methylprednisolone, $500 \mathrm{mg}$ intravenous; then, prednisolone, $1 \mathrm{mg} / \mathrm{kg} / \mathrm{d}$ oral). All patients received induction treatment with basiliximab $(20 \mathrm{mg}$, before and 4 days after transplantation). The dosages of Tac and CsA were adjusted to achieve target trough levels (CsA: first 3 mo, 200-300 ng/mL; subsequently, 100$200 \mathrm{ng} / \mathrm{mL}$ and Tac: first $3 \mathrm{mo}, 8-12 \mathrm{ng} / \mathrm{mL}$; subsequently, 5-8 ng/mL). Oral prednisolone dosage 
was tapered to $20 \mathrm{mg} / \mathrm{d}$ after $1 \mathrm{month}, 10 \mathrm{mg} / \mathrm{d}$ after 2 months and $5 \mathrm{mg} / \mathrm{d}$ after 6 months.

Some recipients received antihypertensive monotherapy $(n=14)$ or combination therapy $(n=30)$ (calcium channel blockers, $\mathrm{n}=35$; beta-blockers, $\mathrm{n}=$ 22; renin-angiotensin-aldosterone-system blockers, $n$ $=16$ and alpha-blockers, $\mathrm{n}=8$ ). Other medications were insulin therapy $(\mathrm{n}=8)$, oral anti-glycemic agents $(\mathrm{n}=4)$, statin $(\mathrm{n}=10)$, vitamin $\mathrm{D}(\mathrm{n}=13)$, bisphosphonate $(\mathrm{n}=5)$ and oral calcium replacement $(n=4)$.

While the mean serum creatinine $(1.52 \pm 0.6 \mathrm{vs}$. $1.29 \pm 0.4 \mathrm{mg} / \mathrm{dL}, p=0.112)$ and UPE $(0.44 \pm 0.83$ vs. $0.52 \pm 1.23 \mathrm{gr} /$ day, $\mathrm{p}=0.754)$ values of groups with normal and low fetuin-A level did not differ, eGFR $\left(54.8 \pm 15.3\right.$ vs. $67.9 \pm 21.1 \mathrm{ml} / \mathrm{min} / \mathrm{m}^{2}, p=$ 0.007) levels are higher in low fetuin A group (Table 2).

No significant differences were observed among two groups in $\mathrm{Ca}$ and $\mathrm{P}$ levels, $\mathrm{Ca} \times \mathrm{P}$ product and normal/pathological DEXA measurement rates. Serum PTH levels are significantly higher in normal fetuin A group $(167.1 \pm 128.1 \mathrm{pg} / \mathrm{mL}$ vs. $95.2 \pm 47.86 \mathrm{pg} / \mathrm{mL}$, $p=0.015$ ). AS (large and small vessel elasticity indexes and total vascular impedance measurements), inflammatory (hsCRP, fibrinogen, fibronektin, TNF$\alpha$, IL-6, IL-8) and oxidative stress (SOD, MDA) parameters shows no significant differences between the two groups (Table 3).

In the study group, fetuin-A levels were positively correlated with creatinine $(\mathrm{r}=0.312, p=0.013)$ and negatively with eGFR $(\mathrm{r}=-0.299, p=0.018)$. There was no correlation between fetuin-A level and other parameters.

\section{DISCUSSION}

Serum fetuin-A levels are significantly increased after successful kidney transplantation compared to CKD patients, but it is still lower than healthy population [18]. Kidney transplantation improves vascular function [19], but early cardiovascular death risk remains increased [20]. In order to reduce CV mortality, it is crutial to understand the clues for progressing CV diseases. For this purpose, traditional and non-traditional cardioavascular risk factors are defined as mentioned in introduction section.

Increased fetuin-A levels after transplantation thought that there is a relationship between low fetuin-

Table 2. Comparison of laboratory results in two groups with normal and low fetuin-A levels

\begin{tabular}{lccc}
\hline & Normal $(\mathbf{n}=\mathbf{3 2})$ & Low $(\mathbf{n}=\mathbf{3 0})$ & $\boldsymbol{p}$ value \\
\hline Hemoglobin (g/dL) & $12.7 \pm 2.0$ & $12.9 \pm 2.1$ & 0.722 \\
Urea [mg/dL, median (min-max)] & $41(15-119)$ & $38.5(23-87)$ & 0.307 \\
Creatinine [mg/dL, median (min-max)] & $1.32(0.94-3.46)$ & $1.27(0.6-2.81)$ & 0.112 \\
eGFR (mL/min/m²) & $54.8 \pm 15.3$ & $67.9 \pm 21.1$ & $\mathbf{0 . 0 0 7}$ \\
Uric acid [mg/dL, median (min-max)] & $6.1(2.9-9.2)$ & $5.7(3.2-10)$ & 0.578 \\
Glucose (mg/dL) & $97.1 \pm 28.2$ & $87.9 \pm 13.9$ & 0.110 \\
T-chol (mg/dL) & $199.0 \pm 48.1$ & $203.0 \pm 44.7$ & 0.740 \\
HDL (mg/dL) & $52.6 \pm 14.9$ & $49.7 \pm 19$ & 0.507 \\
LDL (mg/dL) & $115.4 \pm 36.9$ & $122.1 \pm 33.5$ & 0.456 \\
Triglyceride (mg/dL) & $147(64-390)$ & $134(84-346)$ & 0.916 \\
LVMI (g/m $\left.{ }^{2}\right)$ & $127.8 \pm 27.9$ & $120.2 \pm 28.2$ & 0.295 \\
LVH, n (\%) & $16(50)$ & $10(33.3)$ & 0.184 \\
UPE $[\mathrm{g} / \mathrm{day}$, median (min-max)] & $0.170(0.01-3.35)$ & $0.027(0.01-4.87)$ & 0.754 \\
\hline
\end{tabular}

eGFR $=$ estimated glomerular filtration rate, UPE $=$ urinary protein excretion, $\mathrm{T}$-chol $=$ total cholesterol, $\mathrm{HDL}=$ high density lipoprotein, $\mathrm{LDL}=$ low density lipoprotein, $\mathrm{LVMI}=$ left ventricle mass index, $\mathrm{LVH}=$ left ventricle hypertrophy 
Table 3. Comparison of non-traditional cardiovascular risk factors between the groups with normal and low fetuin-A levels

\begin{tabular}{|c|c|c|c|}
\hline & Normal $(n=32)$ & Low $(n=30)$ & $p$ value \\
\hline Fetuin-A (g/L) & $0.616(0.511-1.079)$ & $0.406(0.153-0.497)$ & $<0.001$ \\
\hline Proteinuria, $\mathrm{n}(\%)$ & $7(21.9)$ & $5(16.7)$ & 0.751 \\
\hline Anemia, n (\%) & $9(28.1)$ & $5(16.7)$ & 0.367 \\
\hline Calcium (mg/dL) & $9.42 \pm 0.71$ & $9.41 \pm 0.57$ & 0.927 \\
\hline Phosphorus (mg/dL) & $3.20 \pm 0.68$ & $3.18 \pm 0.67$ & 0.880 \\
\hline $\mathrm{Ca} \times \mathrm{P}$ & $30.03 \pm 5.71$ & $29.79 \pm 5.82$ & 0.872 \\
\hline PTH $[\mathrm{pg} / \mathrm{mL}$, median (min-max)] & $113.2(33.8-522)$ & $83.9(28-207)$ & 0.015 \\
\hline Osteoporosis, n (\%) & $7(21.9)$ & $4(13.3)$ & 0.511 \\
\hline Osteopenia, n (\%) & $17(53.1)$ & $21(70)$ & 0.173 \\
\hline $\mathrm{C} 1(\mathrm{ml} / \mathrm{mmHgx} 10)$ & $12.75 \pm 5.70$ & $13.57 \pm 4.99$ & 0.565 \\
\hline $\mathrm{C} 2[\mathrm{ml} / \mathrm{mmHgx} 10$, median (min-max)] & $3.9(2.5-7.9)$ & $5.2(1.9-10.2)$ & 0.185 \\
\hline TVI, [median (min-max)] & $141.5(58-295)$ & $125(79-277)$ & 0.477 \\
\hline hsCRP $[\mathrm{mg} / \mathrm{L}$, median (min-max)] & $2.55(0.2-45)$ & $2.1(0.2-30.9)$ & 0.689 \\
\hline Fibrinogen $(\mathrm{mg} / \mathrm{dL})$ & $4.26 \pm 1.24$ & $4.19 \pm 1.23$ & 0.888 \\
\hline Fibronectine $(\mu \mathrm{g} / \mathrm{mL})$ & $112.2 \pm 25.6$ & $115.3 \pm 27.3$ & 0.644 \\
\hline TNF- $\alpha[\mathrm{ng} / \mathrm{mL}$, median (min-max)] & $0.081(0-0.53)$ & $0.050(0.02-0.5)$ & 0.557 \\
\hline IL-6 [ng/mL, median (min-max)] & $1.04(0.76-44.8)$ & $0.89(0.77-23.5)$ & 0.523 \\
\hline IL-8 [ng/mL, median (min-max)] & $6.34(0.4-71.9)$ & $6.71(0.4-33.1)$ & 0.791 \\
\hline TGF- $\beta[\mathrm{pg} / \mathrm{mL}$, median (min-max)]) & $4913(917-47651)$ & $5363(974-29643)$ & 0.817 \\
\hline SOD [U/mL, median (min-max)]) & $977(408-3059)$ & $1140(565-2178)$ & 0.613 \\
\hline GSHpx [U/mL, median (min-max)] & $18.4(9.75-40.5)$ & $15.8(6.46-56.8)$ & 0.987 \\
\hline MDA [nmol/mL, median (min-max)] & $1.04(0.15-3.52)$ & $1.05(0.38-2.67)$ & 0.986 \\
\hline Vitamin C [mg/dL, median (min-max)] & $2.07(0.17-12.7)$ & $2.18(0.51-15.2)$ & 0.234 \\
\hline TAOC [mmol/L, median (min-max)] & $1.15(0.48-5.56)$ & $1.07(0.43-6.37)$ & 0.768 \\
\hline
\end{tabular}

$\mathrm{Ca} \times \mathrm{P}=$ calcium $\times$ phosphorus, $\mathrm{PTH}=$ parathormone, $\mathrm{DEXA}=$ Bone mineral density, $\mathrm{C} 1=$ large vessel elasticity index, $\mathrm{C} 2=$ small vessel elasticity index, TVI $=$ total vascular impedance, $\mathrm{hsCRP}=$ high sensitive $\mathrm{C}$-reactive protein, TNF- $\alpha=$ tumor necrosis factor alpha, IL- $6=$ interleukin 6 , IL- $8=$ interleukin 8 , TGF- $\beta 1=$ transforming growth factor $\beta 1, \mathrm{SOD}=$ superoxide dismutase, $\mathrm{GSHpx}=$ glutathione peroxidase, $\mathrm{TAOC}=$ total antioxidant status, $\mathrm{MDA}=$ malonyl dialdehyde

A levels and glomerular dysfunction [18]. Another study in patients with coronary artery disease reported no relationship between GFR and fetuin-A concentrations [21]. Impaired endothelial functions in transplanted patients were reported in several studies [22-24]. Our data shows that patients with lower fetuin A concentration has greater eGFR $(p=0.007)$, but urea and creatinine levels were similar (Table 2). Several factors may be responsible for the discrepancies including the effect of calcineurin inhibitors [23].

In our cohort, there was no relationship between fetuin-A levels and cholesterol levels, diabetes mellitus and obesity and waist to hip ratios as other studies revealing fetuin-A levels did not correlated renal and metabolic parameters [25].

Cardiovascular events and all-cause mortality rates were significantly increased in transplant 
recipients with low serum fetuin-A levels [26]. The main lesions underlying and ultimately responsible for the clinical manifestations of CVD are atheroma and VC, which often exist together [27]. Marechal et al. [26] have pointed out the difference in the determination of coronary artery and aortic calcification by fetuin-A levels in a multiple linear regression analysis. Although lower serum fetuin-A level was reported as an independent predictor of aortic calcification $(p=0.008)$ no relationship was found in coronary artery calcification [26]. In our study, the number of patients with the history of defined coronary artery disease in the groups with low and normal fetuin-A levels were similar (Table 1).

It is reported that although, coronary artery calcification (CAC) progress is lower in transplanted patient compared with HD patients, but progression still exist. This data explained with the calcification burden during the pre-transplant dialysis period [28, 29]. No relationship between pre-transplant dialysis duration, dialysis modality, transplant duration and fetuin-A levels was observed in our study.

Diabetes mellitus is a risk factor for the presence of CAC in kidney transplant paitents but has not been independently associated with CAC progression [27]. The relationship with diabetes mellitusexistance and fetuin-A levels were not statistically significant in our study.

Serum fetuin-A levels are determined by variants in the plasma cholesterol levels, and a history of smoking, independently of inflammation [26]. Our data showed no difference in cholesterol levels and smoking rates depending on fetuin-A levels.

Kidney transplantation restores endothelial functions. Some studies reported impaired endothelial functions in kidney transplant recipients compared to healthy controls [22-24] which attributed to the effect of calcineurin inhibitors [23]. Inducible nitric oxide inhibition with steroids and calcineurin inhibitors that cause endothelial dysfunction, associated with onset and progression of atherosclerosis and VC. While mycophenolate mofetil has a more favorable effect on endothelial activity than do calcineurin inhibitors and steroids [30], vascular effects of mTOR inhibitors are much more complex. Rapamycin inhibits smooth muscle cell proliferation, while everolimus impairs the vasoactive and antithrombotic function of endothelial cells. In particular, sirolimus inhibits osteoclast formation, unlike steroids and cyclosporine [31]. Our results showed no relationship between fetuin levels and immunosuppressive protocol regimens given.

Hypothetical effect of immunosuppressive therapy on VC could be mediated indirectly, by interfering with post-transplant bone loss, and directly through effects that the same drugs exert on vascular cells (endothelial cells, vascular smooth muscle cells) through intermediation of the RANKL, RANK, and OPG systems [27]. Since osteoporosis rate was higher in normal fetuin A group (7 [21.9\%] vs 4 [13.3\%], $p=$ 0.511 ) and osteopenia rate was higher in low fetuin A group (21 [70\%] vs 17 [53.1\%], $p=0.173)$, both results could not reach statistically significant difference.

Fetuin-A inhibits $\mathrm{Ca}-\mathrm{P}$ precipitation in the serum [32]. An analysis of data obtained from 40,000 patients [33] shows that relative death risk increased 1.5 times in patients whom CaxP is 70 to $75 \mathrm{mg}^{2} / \mathrm{dL}^{2}$, and 1.8 times with a $\mathrm{Ca} \times \mathrm{P}>80 \mathrm{mg}^{2} / \mathrm{dL}^{2}$. A significant increase in mortality risk was associated with even relatively small rises in $\mathrm{Ca} \times \mathrm{P}$ to 50 to $55 \mathrm{mg}^{2} / \mathrm{dL}^{2}$ [33]. In our study $\mathrm{Ca} \times \mathrm{P}$ values were similar in both groups.

Progression of CAC slows down but does not halt after kidney transplantation. There is a strong association between baseline CAC score and CAC progression. A significant improvement in secondary hyperparathyroidism after transplantation favorably affects the progression of CAC. Low $25(\mathrm{OH}) \mathrm{D} 3$ levels are an independent determinant of CAC progression [27]. Ciancialo et. al. [27] reported a significant improvement in secondary hyperparathyroidism after transplantation that slow-down the progression of CAC. No relationship was found between PTH and $\mathrm{VC}$ in a VC progression speed study [34]. Sumida et al. [35] observed strong correlation between carotid plaque and male sex, presence of DM, PTH and VC. DM is a risk factor but has not been identified as an independent risk factor for coronary artery calcification progression [27]. The VC was found associated with the $\mathrm{Ca}$ and $\mathrm{P}$ multiplication $(\mathrm{Ca} \times \mathrm{P})$. In our study, no significant difference was observed in $\mathrm{Ca}, \mathrm{P}$ levels and CaxP between the groups. Number of patients with low bone mineral density between the groups was also similar. However, PTH levels were significantly higher in patients with normal Fetuin-A levels, no correlation was observed between Fetuin-A levels and bone mineralization parameters $(\mathrm{Ca}, \mathrm{P}$, 
$\mathrm{Ca} \times \mathrm{P}, \mathrm{PTH}, \mathrm{DEXA}$ total lumbar score, DEXA total hip score).

Inflammation is an independent predictor of renal allograft loss [36, 37]. Patients with lower fetuin-A levels $(<0.47 \mathrm{~g} / \mathrm{L})$ and higher hsCRP levels $(>4.36$ $\mathrm{mg} / \mathrm{L}$ ) had worse survival, with a risk of death and cardiovascular events 3.48 times higher compared with patients with higher fetuin-A and lower hsCRP combination [26]. Fetuin-A has significant antiinflammatory functions such as inhibition of TGF- $\beta$, tyrosine kinase activity, inflammatory cytokines IL$1 \beta$, IL-6 and TNF- $\alpha[38,39]$. Although fetuin-A acts as a negative acute phase reactant, no correlation was found between fetuin-A levels and markers of inflammation [26]. Our study did not show association between fetuin-A levels and inflammatory markers such as hsCRP, fibronectine, TNF- $\alpha$, IL- 6 , IL- 8 and TGF- $\beta$.

Vascular cellular calcification is indepentantly promoted by oxidative stress which show procalcific effects over oxysterols, oxidized lipids and inflammatory cytokines [40]. It has been shown that, vascular smooth muscle cells' osteochondrocytic differentiation is promoted by the classical oxidant stressor, $\mathrm{H}_{2} \mathrm{O}_{2}$ [41]. Serum SOD, GSHpx and MDA levels were similar, TAOC and Vitamin C levels were not differ between the groups in this study.

Chronic inflammation in CKD patients leads to lower serum fetuin-A levels [42] and that serum fetuin-A showed important association with coronary, valvular calcification and inflammation in CKD patients [43]. In pediatric population serum fetuin-A levels did not identify as an independent predictor of vascular stiffness [44]. Aortic wall stiffness, as reflected by aortic pulse-wave velocity, is a strong predictor of cardiovascular events [45]. Our observation reveals no relationship between fetuin-A levels and total vascular impedance, large and small vessel elasticity indices.

\section{CONCLUSION}

We evaluated the effect of kidney transplantation on cardiovascular risk factors and relationship of serum fetuin-A levels with cardiovascular risk factors by its place in pathophysiology in this study and we observed that although many cardiovascular risk factors improved after kidney transplantation, subclinical inflammation markers were still higher than healthy volunteers. We found no relationship between serum fetuin-A levels and inflammatory, oxidative stress markers and AS parameters. Comparison of non-traditional risk factors that have an important place on cardiovascular illness pathophysiology in large transplanted and healthy volunteer population may contribute to increased survival after kidney transplantation by understanding underlying inflammatory process.Atherosclerosis and most of the cardiovascular risk factors progress silently. Early recognition of these risk factors and identification of high-risk individuals may contribute to the reduction of cardiovascular mortality.

\section{Conflict of interest}

The authors disclosed no conflict of interest during the preparation or publication of this manuscript.

\section{Financing}

The authors disclosed that they did not receive any grant during conduction or writing of this study.

\section{REFERENCES}

[1] Foley RN, Parfrey PS. Cardiovascular disease and mortality in ESRD. J Nephrol 1998;11:239-45.

[2] Meier-Kriesche HU, Schold JD, Srinivas TR, Reed A, Kaplan B. Kidney transplantation halts cardiovascular disease progression in patients with end-stage renal disease. Am J Transplant 2004;4:1662-8.

[3] Kolonko A, Chudek J, Szotowska M, Kuczera P, Wiecek A. Cardiovascular risk factors and markers of atherosclerosis in stable kidney transplant recipients. Transplant Proc 2016;48:1543-50.

[4] Yilmaz MI, Sonmez A, Saglam M, Cayci T, Kilic S, Unal HU, et al. A longitudinal study of inflammation, CKD-mineral bone disorder, and carotid atherosclerosis after renal transplantation. Clin J Am Soc Nephrol 2015;10:471-9.

[5] Sharaf El Din UA, Salem MM, Abdulazim DO. Vascular calcification: When should we interfere in chronic kidney disease patients and how? World J Nephrol 2016;5:398-417.

[6] Ioannou K, Stel VS, Dounousi E, Jager KJ, Papagianni A, Pappas $\mathrm{K}$, et al. Inflammation, endothelial dysfunction and increased left ventricular mass in chronic kidney disease (CKD) patients: a longitudinal study. PLoS One 2015;10:e0138461.

[7] Wang AY, Woo J, Lam CW, Wang M, Chan IH, Gao P, et al. Associations of serum fetuin-A with malnutrition, inflammation, atherosclerosis and valvular calcification syndrome and outcome in peritoneal dialysis patients. Nephrol Dial Transplant 
2005;20:1676-85.

[8] Guerin AP, London GM, Marchais SJ, Metivier F. Arterial stiffening and vascular calcifications in end-stage renal disease. Nephrol Dial Transplant 2000;15:1014-21.

[9] Yildiz A, Fazlioglu M, Ersoy A, Gullulu M, Gullulu S, Yurtkuran M. Arterial elasticity measurement in renal transplant recipients. Transplant Proc 2007;39:1455-7.

[10] Ketteler M, Bongartz P, Westenfeld R, Wildberger JE, Mahnken AH, Bohm R, et al. Association of low fetuin-A (AHSG) concentrations in serum with cardiovascular mortality in patients on dialysis: a cross-sectional study. Lancet 2003;361:827-33.

[11] Cheung AK, Sarnak MJ, Yan G, Dwyer JT, Heyka RJ, Rocco $\mathrm{MV}$, et al. Atherosclerotic cardiovascular disease risks in chronic hemodialysis patients. Kidney Int 2000;58:353-62.

[12] WHO. BMI classification 20.03.2018. Available from: http://apps.who.int/bmi/index.jsp?introPage=intro_3.html.

[13] Devereux RB, Reichek N. Echocardiographic determination of left ventricular mass in man. Anatomic validation of the method. Circulation 1977;55:613-8.

[14] Levey AS, Stevens LA, Schmid CH, Zhang YL, Castro AF, 3rd, Feldman HI, et al. A new equation to estimate glomerular filtration rate. Ann Intern Med 2009;150:604-12.

[15] Joist H, Brennan DC, Coyne DW. Anemia in the kidneytransplant patient. Adv Chronic Kidney Dis 2006;13:4-10.

[16] Lebreton JP, Joisel F, Raoult JP, Lannuzel B, Rogez JP, Humbert G. Serum concentration of human alpha 2 HS glycoprotein during the inflammatory process: evidence that alpha 2 HS glycoprotein is a negative acute-phase reactant. J Clin Invest 1979;64:1118-29.

[17] Mosteller RD. Simplified calculation of body-surface area. N Engl J Med. 1987;317:1098.

[18] Caglar K, Yilmaz MI, Saglam M, Cakir E, Kilic S, Eyileten T, et al. Endothelial dysfunction and fetuin A levels before and after kidney transplantation. Transplantation 2007;83:392-7.

[19] Litwin M, Wuhl E, Jourdan C, Trelewicz J, Niemirska A, Fahr K, et al. Altered morphologic properties of large arteries in children with chronic renal failure and after renal transplantation. J Am Soc Nephrol 2005; 16:1494-500.

[20] Kiberd B, Keough-Ryan T, Panek R. Cardiovascular disease reduction in the outpatient kidney transplant clinic. Am J Transplant 2003;3:1393-9.

[21] Ix JH, Chertow GM, Shlipak MG, Brandenburg VM, Ketteler M, Whooley MA. Fetuin-A and kidney function in persons with coronary artery disease--data from the Heart and Soul Study. Nephrol Dial Transplant 2006;21:2144-51.

[22] Mark PB, Murphy K, Mohammed AS, Morris ST, Jardine AG. Endothelial dysfunction in renal transplant recipients. Transplant Proc 2005;37:3805-7.

[23] Mercanoglu F, Turkmen A, Kocaman O, Pinarbasi B, Dursun M, Selcukbiricik F, et al. Endothelial dysfunction in renal transplant patients is closely related to serum cyclosporine levels. Transplant Proc 2004;36:1357-60.

[24] Passauer J, Büssemaker E, Lassig G, Gross P. Kidney transplantation improves endothelium-dependent vasodilation in patients with endstage renal disease. Transplantation 2003;75:1907-10.
[25] Roos M, Heinemann FM, Lindemann M, Horn PA, Lutz J, Stock K, et al. Fetuin-A pretransplant serum levels, kidney allograft function and rejection episodes: a 3-year posttransplantation follow-up. Kidney Blood Press Res 2011;34:328-33.

[26] Marechal C, Schlieper G, Nguyen P, Kruger T, Coche E, Robert A, et al. Serum fetuin-A levels are associated with vascular calcifications and predict cardiovascular events in renal transplant recipients. Clin J Am Soc Nephrol 2011;6:974-85.

[27] Cianciolo G, Capelli I, Angelini ML, Valentini C, Baraldi $\mathrm{O}$, Scolari MP, et al. Importance of vascular calcification in kidney transplant recipients. Am J Nephrol 2014;39:418-26.

[28] Min JK, Lin FY, Gidseg DS, Weinsaft JW, Berman DS, Shaw LJ, et al. Determinants of coronary calcium conversion among patients with a normal coronary calcium scan: what is the "warranty period" for remaining normal? J Am Coll Cardiol 2010;55:1110-7.

[29] McCullough PA. Annual progression of coronary calcification in trials of preventive therapies. Arch Intern Med 2009; 169:2064-70.

[30] Nickel T, Schlichting CL, Weis M. Drugs modulating endothelial function after transplantation. Transplantation 2006;82(1 Suppl):S41-6.

[31] Westenfeld R, Schlieper G, Woltje M, Gawlik A, Brandenburg V, Rutkowski $\mathrm{P}$, et al. Impact of sirolimus, tacrolimus and mycophenolate mofetil on osteoclastogenesis-implications for post-transplantation bone disease. Nephrol Dial Transplant 2011;26:4115-23.

[32] Schafer C, Heiss A, Schwarz A, Westenfeld R, Ketteler M, Floege J, et al. The serum protein alpha 2-Heremans-Schmid glycoprotein/fetuin-A is a systemically acting inhibitor of ectopic calcification. J Clin Invest 2003;112:357-66.

[33] Block GA, Klassen PS, Lazarus JM, Ofsthun N, Lowrie EG, Chertow GM. Mineral metabolism, mortality, and morbidity in maintenance hemodialysis. J Am Soc Nephrol 2004;15:2208-18. [34] Sigrist MK, Taal MW, Bungay P, McIntyre CW. Progressive vascular calcification over 2 years is associated with arterial stiffening and increased mortality in patients with stages 4 and 5 chronic kidney disease. Clin J Am Soc Nephrol 2007;2:1241-8.

[35] Sumida Y, Nakayama M, Nagata M, Nakashita S, Suehiro T, Kaizu Y, et al. Carotid artery calcification and atherosclerosis at the initiation of hemodialysis in patients with end-stage renal disease. Clin Nephrol 2010;73:360-9.

[36] Ombrellino M, Wang H, Yang H, Zhang M, Vishnubhakat J, Frazier A, et al. Fetuin, a negative acute phase protein, attenuates TNF synthesis and the innate inflammatory response to carrageenan. Shock 2001;15:181-5.

[37] Goldfarb-Rumyantzev AS, Naiman N. Genetic predictors of acute renal transplant rejection. Nephrol Dial Transplant 2010;25:1039-47.

[38] Dervisoglu E, Kir HM, Kalender B, Caglayan C, Eraldemir C. Serum fetuin--a concentrations are inversely related to cytokine concentrations in patients with chronic renal failure. Cytokine 2008;44:323-7.

[39] Heiss A, DuChesne A, Denecke B, Grotzinger J, Yamamoto $\mathrm{K}$, Renne T, et al. Structural basis of calcification inhibition by alpha 2-HS glycoprotein/fetuin-A. Formation of colloidal 
calciprotein particles. J Biol Chem 2003;278:13333-41.

[40] Mody N, Parhami F, Sarafian TA, Demer LL. Oxidative stress modulates osteoblastic differentiation of vascular and bone cells. Free Radic Biol Med 2001;31:509-19.

[41] Tyson KL, Reynolds JL, McNair R, Zhang Q, Weissberg PL, Shanahan CM. Osteo/chondrocytic transcription factors and their target genes exhibit distinct patterns of expression in human arterial calcification. Arterioscler Thromb Vasc Biol 2003;23:489-94.

[42] Cozzolino M, Galassi A, Biondi ML, Turri O, Papagni S, Mongelli N, et al. Serum fetuin-A levels link inflammation and cardiovascular calcification in hemodialysis patients. Am J Nephrol 2006;26:423-9.
[43] El-Shehaby AM, Zakaria A, El-Khatib M, Mostafa N. Association of fetuin-A and cardiac calcification and inflammation levels in hemodialysis patients. Scand J Clin Lab Invest 2010;70:575-82.

[44] van Summeren MJ, Hameleers JM, Schurgers LJ, Hoeks AP, Uiterwaal CS, Kruger T, et al. Circulating calcification inhibitors and vascular properties in children after renal transplantation. Pediatr Nephrol 2008;23:985-93.

[45] Kuzniar J, Porazko T, Klinger M. Relationship between fetuin-A concentration, elevated levels of inflammatory markers, and arterial wall stiffness in end-stage kidney disease. J Ren Nutr 2008;18:83-6. 